\title{
LA MATERNIDAD DESDE LA EXPERIENCIA DE MUJERES QUE VIVEN CON VIH ATENDIDAS EN EL Hospital de Las Culturas, en Chiapas, México*
}

\author{
Mothers with HIV: their experiences \\ at Hospital de Las Culturas, Chiapas, Mexico
}

\author{
María Ximena Viñas PéreZ** \\ Guadalupe del Carmen Álvarez Gordillo**** \\ ENRIQUe ERosa Solana**** \\ Angélica Aremy Evangelista García***** \\ Georgina SÁnchez RamíREZ********
}

\section{RESUMEN}

Esta investigación aborda la significación de la maternidad en mujeres que viven con VIH. Se parte del supuesto del VIH como enfermedad estigmatizada y como punto de quiebre en la trayectoria de vida. Se entrevistaron a ocho mujeres en diferente situación de maternidad que acudían a los Servicios de Atención Integral del Hospital de Las Culturas, en San Cristóbal de Las Casas, Chiapas. Los resultados indican tensiones y contradicciones respecto de la maternidad con la presencia del VIH. El riesgo de transmisión, la posibilidad del daño y la sensación de haber fallado como madres son elementos que forman parte de la experiencia y conforman una idea de incompatibilidad entre ser madre y vivir con VIH.

Palabras Clave: Maternidad, VIH, SIDA, estigma.

\footnotetext{
* Este artículo es resultado de una investigación realizada en el marco de la Maestría en Ciencias en Recursos Naturales y Desarrollo Rural de El Colegio de la Frontera Sur, unidad San Cristóbal de Las Casas.

** El Colegio de la Frontera Sur. Correo electrónico: ximena_vinas@hotmail.com.

***El Colegio de la Frontera Sur. Correo electrónico: galvarez@ecosur.mx.

**** ECOSUR Sureste. Correo electrónico: galvarez@ecosur.mx.

***** El Colegio de la Frontera Sur. Correo electrónico: aevangel@ecosur.mx.

*******El Colegio de la Frontera Sur. Correo electrónico: gsanchez@ecosur.mx.
} 


\section{Abstract}

This investigation is about the significance of motherhood for women who live with HIV. We assume that HIV is stigmatized disease, and a breaking point in their lives. This investigation is based on the interviews of eight women in different motherhood situation who went to the Integral Attention Services in Hospital de Las Culturas, San Cristobal de Las Casas in Chiapas. The results show tensions and contradictions between being a mother and having HIV. The risk of transmission, the possibility of harming or hurting others, and the sensation of having failed as a mother. These are elements that are an important part of the experience and conform the idea of incompatibility of being a mother and having HIV.

KEYWORDS: MOTHERHOOD, HIV, STIGMA. 


\section{INTRODUCCIÓN}

El diagnóstico del VIH y el sida enfrenta a las personas a los imaginarios sociales sobre el virus y la enfermedad, a sus propias historias, relaciones y contextos (Grimberg, 2003). Por lo tanto, representa un punto de quiebre que tiene impactos sobre el cuerpo y la cotidianidad, en el terreno de lo subjetivo, donde pueden replantearse valores, ideas y proyectos (Rodríguez, 2010). En este contexto, la maternidad se convierte en un espacio de conflicto, en el que confluyen diferentes discursos y simbolizaciones sobre la enfermedad y el estigma.

Esta investigación estuvo orientada hacia la dimensión de la experiencia de vivir con VIH, mediada por el contexto sociocultural, los acontecimientos específicos en torno al hecho de saber que viven con VIH, los significados en relación con la enfermedad, los roles y relaciones de género. Todo ello, para dar cuenta de algunos elementos que participan en la forma en que se significa la maternidad en un contexto de estigmatización. Así, el objetivo de este artículo es presentar y discutir los resultados de una investigación cualitativa sobre los significados de la maternidad en mujeres que viven con VIH.

\section{ANTECEDENTES}

Algunas de las investigaciones que han abordado el tema tienen como eje de análisis la perspectiva de género para dimensionar la forma en que mujeres y hombres se relacionan con el VIH. Grimberg (2003) ha explorado, desde esta perspectiva, la dimensión corporal de la experiencia de vivir con VIH. Su tesis principal sostiene que el VIH, como construcción social, confronta metáforas modeladas por el género, que se viven en la experiencia cotidiana. Sus principales hallazgos describen vivencias de tensión; el cuerpo toma importancia radical y se significa como un freno que impide la realización de algunas actividades, por lo que se configura como una amenaza para sí mismo y para los demás. En el caso de las mujeres, esta experiencia "confronta las construcciones sociales hegemónicas del cuerpo femenino como objeto erótico" (Grimberg, 2003, p. 91) y como cuerpo que tiene la capacidad de crear otra vida. La transmisión vertical, ${ }^{1}$ como posibilidad o como hecho, configura la experiencia del cuerpo en un objeto doblemente negativo: "como

\footnotetext{
1 Se refiere a la transmisión del virus durante el embarazo, el parto o la lactancia. También es llamada transmisión materno infantil y, en algunos países, transmisión paterno infantil (ONUSIDA, 2011)
} 
'agente de contagio', como amenaza para otro, o como objeto vacío de sentido" (Grimberg, 2003, p. 91).

La sexualidad se expresa como un espacio conflictivo para muchas mujeres que viven con VIH, por diversas razones. Principalmente, se tiene en cuenta la existencia de una construcción dominante de la sexualidad que marca límites entre lo aceptable, lo "normal" y lo que no lo es. Algunos aspectos de la moral sexual dominante se manifiestan en la población femenina que vive con VIH, como el miedo a la sospecha de promiscuidad, que deviene en el ocultamiento del diagnóstico y los sentimientos de culpa (Grimberg, 2000). En este escenario, la maternidad no queda marginada del terreno de la estigmatización. Según Kendall y Pérez (2004), el cuerpo y la sexualidad femenina sufren una desvalorización ante la presencia del VIH o el sida, pues se supone que el cuerpo "ya no es apto" para la sexualidad reproductiva o la crianza.

Long (2009) describe los conflictos y contradicciones que experimentaron las mujeres en relación con el embarazo y el parto; por un lado, un momento esperado por el nacimiento del hijo o hija y, por el otro, el diagnóstico de VIH o el sida como un suceso que se experimenta con angustia e incertidumbre. La concepción supone un evento en el que surge la vida y, al mismo tiempo, la asociación del VIH o el sida con la posibilidad de muerte y la incertidumbre acerca de la transmisión alimentan esta situación contradictoria.

Desde un enfoque socioantropológico, Pedrosa (2004) se interesó en la vivencia de las mujeres en el embarazo, e identificó los principales cambios ocurridos a partir del diagnóstico médico en sus esferas sociales cercanas y en relación con el ocultamiento de la enfermedad. Algunos de sus principales hallazgos dan cuenta de la interrelación entre el género, el estigma y las condiciones sociales de marginación que representan reacomodos en su nueva identidad y en relación con los demás. En este escenario, la ilusión de ser madre se convierte en una experiencia angustiosa. Ésta es una situación en la que se encuentran por lo menos dos discursos: desde la cultura, el hecho casi incuestionable de la reproducción como núcleo de la identidad femenina, y la creencia prevaleciente de que la mujer ya no debería tener hijos por vivir con VIH (Ingram y Hutchinson, 2010).

Desde la biomedicina, la salud reproductiva de las mujeres que viven con VIH se ha concentrado en el bebé no nacido y en la prevención de la transmisión vertical (Loutfy et al., 2013). Trabajos de Argentina, Brasil y México (Pecheny, et al, 2012; Biagini, Griatis y Giri 2008; Segurado y Pavia, 2007) han reconocido limitaciones en la atención y el cuidado de la salud reproductiva y los derechos sexuales de las mujeres 
que viven con VIH. El deseo, la posibilidad de embarazo, las dudas y la orientación en las diferentes etapas no son motivos de consulta en el ámbito médico. La falta de consejería y de acompañamiento se identifican como las principales barreras, junto el estigma y la discriminación. En México, la depresión es más alta en las mujeres con VIH e infecciones de transmisión sexual (ITS) (Lartigue et al., 2004). En general, existen pocos espacios donde se hable de sexualidad o de opciones reproductivas, ya que el énfasis en la prevención de la transmisión pareciera negar esas posibilidades. Al ser el VIH y el sida enfermedades de transmisión sexual, el cuerpo y la sexualidad femeninas parecen estar ausentes en sus discursos legítimos (Herrera et al., 2009).

Se requiere un enfoque interdisciplinario y con perspectiva de género en relación con la atención sobre sexualidad y reproducción. La incorporación de mujeres y hombres que viven con VIH a este tipo de servicios sería clave para la mejora de los derechos sexuales, reproductivos y la salud en general, además de aportar a la sensibilidad y respeto de parte de los trabajadores de la salud (Gogna et al., 2009).

\section{EL VIH Y LA MATERNIDAD COMO CONSTRUCCIÓN SOCIAL}

Este estudio rescata una dimensión social y subjetiva del VIH y el sida entendida como un fenómeno complejo: "una construcción social e histórica compleja, de múltiples dimensiones (biológica, económica, política, cultural) que configura y se configura en un campo de disputa de variables y correlaciones de fuerza entre diversos actores con diferentes, y frecuentemente opuestos, intereses, políticas y prácticas" (Grimberg, 2003, p. 81). El contexto en el que se ha desarrollado tal construcción social acerca del VIH se conforma de sentidos moralistas, normativos y estigmatizantes. Alrededor de la búsqueda de culpables, la idea de "contagio" y su asociación con la muerte, se conforman el miedo, la idea de castigo y la culpa.

En este estudio se retomó el concepto de estigma para entender los elementos que estructuran la experiencia. Goffman (1963) define el estigma como un atributo desacreditador que posee una persona o un grupo, que tiene efectos en su identidad y en la relación con los demás. Este atributo no es un fenómeno aislado; para que exista debe partir de una noción de normalidad, un consenso social sobre lo aceptable (Goffman, 1963). El estigma, por lo tanto, forma parte de la configuración del orden social; es más una relación de devaluación que un atributo o una categoría estática; descansa profundamente en las estructuras de género, económicas, raciales y sexuales de cada sociedad (Parker y Aggleton, 2002). 
En el planteamiento de la maternidad se reconocen diversos aspectos (biológicos, sociales, culturales, subjetivos, simbólicos e históricos) que no se perciben aislados, sino entretejidos. Su concepción resulta de la convergencia de discursos que atienden a diferentes significados y prácticas. La maternidad,

lejos de ser sólo un hecho natural, es una construcción cultural multideterminada, definiday organizada por normas que se desprenden de las necesidades de un grupo social específico y de una época definida de su historia, conformando un fenómeno cruzado por discursos y prácticas sociales condensados en un imaginario complejo y poderoso que al mismo tiempo produce y resulta del género (Palomar y Suarez, 2007, p. 310).

La maternidad, más que una función, es una experiencia, disímil, que se conforma en el plano de lo íntimo y lo social (Long, 2009). Desde el enfoque feminista, este tema ha sido abordado ampliamente. En líneas generales, la crítica se dirige a la visualización histórica de la maternidad como evento incuestionable del hecho de ser mujer, bajo normativas sobre la edad y las circunstancias esperables para que las mujeres se conviertan en madres; entre ellas, una relación heterosexual, monógama e institucionalizada. Se critica la asociación de la maternidad como núcleo de la identidad femenina y el ideal común que proporciona a todas las mujeres (Salleti, 2008). La función materna, como función social, refuerza las ideas tradicionales sobre la maternidad, el rol de los sexos, reproduciendo los valores dominantes y la ordenación jerárquica de la sociedad (Everingham, 1997).

Badinter (1981) es reconocido por sus cuestionamientos respecto del amor y el instinto maternales. Sus argumentos van dirigidos a replantear lo innato en estas dos construcciones, en las que destacan la exigencia social enmarcada en la moral y los valores de las sociedades. Critica la concepción de una conducta universal y necesaria sobre la maternidad, una sola actitud maternal y un único deseo en la vida de una mujer. Otorga la cualidad de mito al instinto que sostiene al amor maternal, puesto que hay diversidad de sentimientos según la historia personal, la cultura, las frustraciones y ambiciones (Salleti, 2008). En concreto, se afirma que no hay una sola forma de ser madre que denote la existencia de un instinto o una actitud maternal (Badinter, 1981).

Tubert (1996) distingue la maternidad como institución del cuidado de los hijos y las hijas para identificar la dominancia de los discursos. La significación de la maternidad se conforma de imágenes, atributos e ideales que denotan estereotipos y mandatos. En este escenario, surgen los ideales que dan cuenta de la forma en que 
se debe ejercer la maternidad. Lejos de describir categorías inamovibles, Palomar (2004) categoriza a "las buenas y las malas madres". A las primeras se les atribuyen cualidades de entrega a su función, sacrificio y protección; a sus contrapartes, las que incumplen con exigencias, las que se alejan de los estándares legitimados por los ámbitos médico y jurídico, las que no demuestran deseo ni amor maternal (Palomar y Suarez, 2007).

Estas exigencias, aspiraciones e ideales, que son parte de la maternidad como función social, son experimentadas desde las subjetividades de forma conflictiva y tensa (Sanhueza, 2005); de allí, la necesidad de estudiar las historias personales en los contextos. Más allá de ser entendida como una imposición social o un hecho natural, tanto en el ejercicio como en el deseo de ser madre, las mujeres no son entes pasivos; los significados se construyen activamente, la subjetividades se modifican (Everingham, 1997).

La vivencia de la maternidad, el deseo de convertirse en madre y el amor materno no responden a un ideal, ni se reducen a una medida en común; existe diversidad en el deseo, el sentir y el hacer. Tubert (1996) sostiene que las categorías de lo femenino y lo maternal mantienen relaciones complejas, no coinciden totalmente, ni son disociables completamente; "la categoría de madre no agota totalmente a la de la mujer y, por otra parte, la maternidad no incluye la totalidad de la reproducción" (Tubert, 1996, p. 8).

\section{Apuntes metodológicos}

La investigación fue planteada desde la metodología cualitativa porque ésta permite el acercamiento y la comprensión de los significados que las personas otorgan a sus acciones, experiencias y acontecimientos. Este enfoque implica una forma de pensar y construir vínculos con la realidad, en la que se proyectan relaciones de conocimiento y se interpretan los datos vinculándolos con la teoría (Ponce, 2010).

El giro hacia los métodos cualitativos significa la adopción de un paradigma epistemológico alternativo al enfoque positivista. Supone que la realidad se construye socialmente y no es independiente de los individuos. Esta realidad es cognoscible mediante la interpretación, y ésta es reflexiva respecto del contexto y el discurso (Castro, 1996).

En esta investigación, este planteamiento permitió conocer temas sensibles y de índole privada en relación con sentimientos y valores personales sobre el tema. 
Se privilegió la voz de los actores, entendidos como aquellos que producen y reproducen la estructura social y de significados (Menéndez, 1997).

Se partió del supuesto de concebir la enfermedad como un fenómeno multidimensional (Martínez, 2008). Por un lado, el concepto de enfermedad construido desde la biomedicina alude a las anormalidades en la estructura y en la función de los órganos o sistemas; comprende, por lo tanto, una serie de patologías. Por otro lado, aunque íntimamente relacionados, se define el padecimiento, el cual implica la manera en que los sujetos perciben, interpretan y responden a las manifestaciones y efectos de la enfermedad; involucra también las redes sociales más cercanas como la familia (Mercado Martínez et al., 1999). En este sentido, nos interesó retomar la experiencia de vivir con VIH para plantear la comprensión desde el sujeto y su contexto cultural particular.

Para la generación de datos se recogieron relatos de vida, en el marco de la entrevista abierta, ya que permite la exploración y profundización sobre los temas de la realidad. Las entrevistas y los relatos posibilitaron la creación de un escenario favorable para la generación de conocimientos a través de la reconstrucción del lenguaje y de la problemática (Vela, 2001).

Los relatos de vida forman parte de la tradición de métodos biográficos que se interesan por la historia vivida de las personas o una parte de ella. Estos métodos propician la narrativa y hacen posible la exploración de los temas de la realidad y la profundización en éstos. Los relatos suceden cuando se narra un episodio de la experiencia, el cual es susceptible de análisis y permite observar la manera en que el fenómeno se construye biográficamente en las personas (Bertaux, 1980; Cornejo y Mendoza, 2008).

El punto de partida de los relatos fue la experiencia de las mujeres en torno al momento en que se enteraron de que vivían con VIH. Esto dio origen a la narración de los sucesos considerados importantes y facilitó la profundización en aquellos elementos relacionados con la maternidad. Las entrevistas fueron grabadas y transcriptas textualmente. Asimismo se realizaron anotaciones de campo y se generaron expedientes de cada uno de los casos.

El proceso de análisis se llevó a cabo en dos etapas de naturaleza dialógica. En un primer momento, se revisó cada uno de los relatos y se identificaron las categorías planteadas que resultaron de la construcción del problema, la revisión teórica y la guía de entrevista. Este primer reconocimiento fue de índole exploratorio y descriptivo. Se tomaron en cuenta las circunstancias alrededor del diagnóstico, la forma en que se posicionan frente a la posibilidad de ser madre que vive con VIH, 
los principales conflictos, miedos y preocupaciones. Se buscaron patrones, temas y regularidades, pero también contrastes y paradojas (Delamont 1992, cit. en Coffey y Atkinson, 2003). En un segundo momento, como parte de una lectura transversal, se realizó una integración que surgió a partir de la reflexión sobre las categorías identificadas en cada uno de los casos.

\section{Contexto De estudio}

La investigación, que contó con la presentación y aprobación de tres diferentes comités de ética, ${ }^{2}$ se llevó a cabo en el Servicio de Atención Integral $\left(\mathrm{SAI}^{3}\right)$ del Hospital de Las Culturas, en la ciudad de San Cristóbal de Las Casas (SCLC), estado de Chiapas. Al momento de la investigación, el SAI contaba con una médica, un médico y personal de enfermería para cubrir la atención toda la semana. Los y las pacientes se citan, en su mayoría, una vez al mes para su atención y entrega de medicamentos. Desde ese consultorio son canalizados a los diferentes especialistas y servicios con los que cuenta el hospital, además son trasladados de manera gratuita a Tuxtla para el recuento de CD4 y carga viral. ${ }^{4}$

En el SAI se centraliza la atención de las personas que residen en la zona de los Altos de Chiapas. Ésta es la región con mayor cantidad de población indígena del estado (tzotziles y tzeltales); comprende 17 municipios conformados por localidades, en su mayoría, rurales. Se caracteriza por diferentes actividades económicas, entre las que destacan la agricultura y el turismo. Además, SCLC, por ser un lugar céntrico dentro de las poblaciones y comunidades cercanas, es epicentro de diferentes intercambios comerciales y culturales, como resultado de la afluencia de diferentes visitantes (tanto nacionales como extranjeros). Al mismo tiempo, se caracteriza por diferentes expresiones culturales y políticas, como resultado de los orígenes diversos de sus habitantes.

En los últimos años, el registro de casos de VIH y sida en el estado y en la región afronta por lo menos dos situaciones particulares. Por un lado, la falta de información y ubicación de las personas que viven con VIH, tanto población

2 Comité de Ética para la Investigación de El Colegio de la Frontera Sur, Comisión de Bioética del Estado de Chiapas y Comité de Ética del Hospital de las Culturas.

3 El SAI tiene cerca de doce años de funcionar en la ciudad y aproximadamente dos años de estar en este hospital. Depende de la Coordinación Estatal del Programa VIJH/SIDA/ITS y de la Secretaría de Salud.

4 Éstos son exámenes periódicos de control. El recuento de células CD 4 proporciona información sobre el estado inmunológico, y la carga viral se refiere a la cantidad de virus en la sangre. 
indígena como no indígena, debido al subregistro causado por la escasez de dispositivos de detección, prevención y atención en las instituciones de salud (CDI, 2011). Por otro lado, se ha documentado un incremento de los reportes de casos debido a la implementación de estrategias de detección de otras enfermedades como el cáncer cérvicouterino (CENSIDA, 2009). Actualmente, el SAI atiende a 171 personas que viven con $\mathrm{VIH}$, de las cuales 20 son mujeres (entrevista con la encargada del SAI).

En el contexto nacional, Chiapas ocupa el octavo lugar en número de casos acumulados y el cuarto en número de defunciones, aproximadamente 41 por ciento de los 2023 casos son mujeres (CENSIDA, 2014). Se encuentra entre las entidades con mayor porcentaje de casos de VIH y sida en esta población; 90.6 por ciento ha sido el resultado de relaciones sexuales no protegidas (CENSIDA, 2014). Adicionalmente, Aguilar y Jiménez (2007) han reportado una disminución de la relación respecto de los hombres, que, a diferencia de la nacional, la cual es de 5 a 1 , en el estado es de tres hombres por cada mujer. En todo el país, en el periodo de 1993 a 2013 se incrementó seis veces debido a condiciones estructurales de desigualdad social que propician mayor vulnerabilidad en las mujeres.

\section{LAS PARTICIPANTES}

Se consideraron a todas las mujeres que acudían al SAI entre abril y julio de 2014. El principal criterio de selección fue el interés y la aceptación por participar. Se diseñó una estrategia que permitiera el acercamiento a las mujeres respetando y cuidando la confidencialidad. La investigadora principal no tuvo contacto con ninguna mujer asistente al SAI sin consentimiento. La invitación fue realizada por la médica encargada. En un primer encuentro, ella les comentó acerca de la investigación, el objetivo del estudio y los términos de la participación. Al confirmar su interés fueron contactadas por la investigadora principal del estudio, quien procedió a explicar los acuerdos contenidos en el consentimiento informado y a la firma de éste. Se integraron ocho mujeres con las que se realizaron varios encuentros para alcanzar la profundidad en la entrevistas (véase el cuadro 1).

Esta selección resultó en una riqueza de las participantes en cuanto a experiencias de maternidad. Formaron parte de este estudio mujeres madres de hijos e hijas que viven y no con el VIH, que tienen hijos fallecidos a causa de enfermedades relacionadas con el VIH y que no han sido madres. Esta diversidad permitió la movilidad 


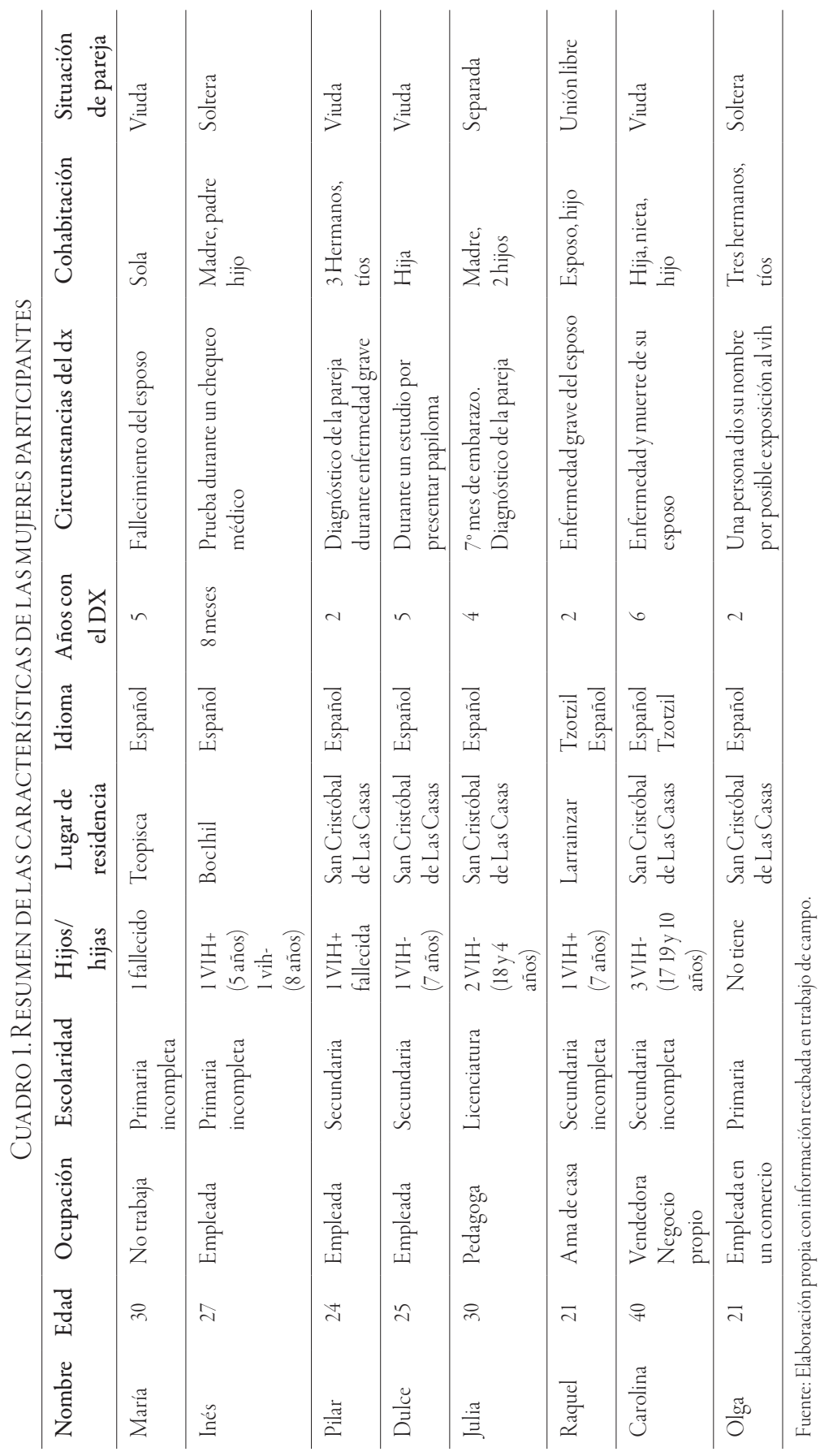


en el análisis, alimentando las contradicciones y las recurrencias, fomentando la comprensión de las significaciones a partir de diferentes escenarios.

\section{De LOS SIGNIFICADOS DE LA MATERNIDAD Y EL VIH. ¿DE QUIÉN ES LA CULPA?}

En las entrevistas emergió como tema relevante lo sucedido en torno al momento en que se enteraron de que vivían con VIH. Se abordaron las circunstancias, reacciones, consecuencias y cambios, así como aspectos que formaron parte de su experiencia. En la mayoría de los casos, éste fue el punto de partida para las narraciones, y generó un debate acerca del origen de la culpa. La profundización en este proceso encierra valoraciones morales y da luz sobre el estigma relacionado con el VIH y el sida. Además, al ser un momento de incertidumbre, debido a que no puede conocerse con exactitud cómo y cuándo sucedió la transmisión, da lugar a suposiciones, explicaciones, a veces incompletas, y a silencios.

En los discursos que conforman el VIH y el sida, las personas son estigmatizadas; sin embargo, no todas tienen la misma responsabilidad. Estas mujeres conviven con la idea de los culpables y las víctimas, en una relación causal con algún comportamiento o su omisión. La predisposición, por hablar en términos de responsabilidad, comprende a figuras como el personal de salud, la familia y las personas que lo padecen. Estas ideas sobre la culpabilidad y la victimización conforman las narraciones que le otorgan sentido a la experiencia de vivir con VIH. Las personas se identifican, identifican y son identificadas en alguno de los dos extremos.

La discusión para explicar el origen de la transmisión del VIH incluye el señalamiento de una persona, un comportamiento, una decisión.

Al frente de él no le dije nada, no le reproché ni nada, tranquila. Murió y la gente decía por qué no lloraba, pero yo tenía un rencor dentro de mí muy grande de que por culpa de él yo también podía estar infectada del VIH. Pero pasó el tiempo, y siempre el doctor, era un doctor que me atendía antes y él me mandaba a hacer análisis a Tuxtla, y yo tenía un rencor a todos los hombres, no podía ver un hombre, que me daba coraje. Yo no estuve con ningún hombre antes de que me juntara con él,y como yo no me casé, sino que nos juntamos nada más, yo no sé qué hacía antes, con quién se metía. Él me lo transmitió, porque ya así juntos no tardamos creo que dos años y medio, y luego murió. Entonces yo puedo decir que yo no, yo no había tenido pareja antes. Por eso digo que él, era mayor, porque si no ¿̇de dónde? 
Yo supe desde el principio [...] (30 años de edad, un bebé fallecido posiblemente debido a una enfermedad relacionada con el VIH).

Pues me tomó muy triste... muy triste y muy enojada... con él más que nada. Pero yo después dije: si Dios eso quiere, que a mí me tocó.... algo hice o qué fue... porque dije yo ¿por quéa mí me toco? Este... pero lo voy a aceptar, porque ya luego me dijeron que había medicamento... lo voy a aceptar. Pero sí me quedé con mucho coraje. Nunca me dijo, nunca. Nunca me enteré. Pues yo, como me decía el médico que a lo mejor él se inyectaba droga o alguien que, que se inyectara droga también. Podía haber tenido relación sexual con algún hombre homosexual o con alguna mujer, o no sabemos, dice. Pues, la verdad, no sé, yo no sé. No sé qué fue lo que pasó. Nunca me comentó. Y él nunca supo, nunca supo. ¿Será que lo supo y él nunca me lo comentó? Porque qué mal, porque ya desde cuando... mucho antes lo hubiera yo tratado con más tiempo, este... y él... Yo a veces me pregunto que si él viviera, no sé si yo lo hubiera aceptado así. Para mí era mejor que ya se fuera y me quedé sola, libre y sin reprocharle a cada rato, porque yo siento que si él viviera y viviera conmigo, creo que tampoco hubiera podido vivir. Porque yo siempre iba a andar con un coraje... sí, de que él me contagió, porque... yo en mi casa y todo... Pues él dice que se había ido a buscar dinero, pero él se iba a ir a trabajar, y no a hacer sonseras ahí en Cancún, de eso se trataba. Eso era mi coraje ( 40 años de edad, dos hijas y un hijo, ninguno vive con VIH).

El debate más amplio se extiende hacia matices de carácter moral; comprende la necesidad de expresar quién estuvo bien y quién mal, o si se está exenta de la culpa, o dentro del terreno de lo indebido, de lo no aceptado. En la mayoría de los casos, la figura masculina, como pareja estable o esposo, es el objeto principal de culpa. En estos casos, las mujeres recordaron sentirse enojadas. Además, fue un evento sorpresivo, porque ninguna se percibía en riesgo. La fidelidad que se espera de una pareja no permite pensar en la necesidad de utilizar algún método de prevención. La presencia del VIH significó, en ese contexto, un engaño o resultado de una relación previa por parte de la pareja, así como la sospecha o certeza de que su pareja les ocultaba el virus. En estos casos, la culpa se deposita fuera de sí mismas, ya que fueron eventos de carácter inevitable y sorpresivo. Esto implica la protección de la identidad, porque continúa siendo una persona que no hizo algo "incorrecto"; sin embargo, no se encuentra fuera de la estigmatización asociada a vivir con VIH y sigue siendo propensa a ser señalada por otras personas.

Van a decir que soy una cochina [baja la voz], que me metí con un hombre que estaba así... A lo mejor que porque yo andaba por ahí con varios y por eso tengo esta enfermedad (27 años, un hijo que vive con VIH). 
Y la poca gente que sabe lo que tengo pues se han de preguntar ¿y ahora, cómo es que tiene eso y no está ni casada? Bueno, los que supieron que estuve casada, bueno, van a pensar que tuve relaciones con muchos, no sé [...] (24 años, una hija fallecida por enfermedad asociada al VIH).

Para aquellas mujeres que se culpan e identifican en sus actitudes las causas de sus comportamientos, las consecuencias resultan diferentes. La idea es compartida, hay responsables, pero, en este caso, las que transgredieron fueron ellas. La transgresión corresponde a eventos relacionados con el ejercicio de la sexualidad fuera de lo considerado "normal" y con comportamientos calificados como inapropiados. Esto es fuente de vergüenza y, por lo tanto, coexiste con un sentido de merecimiento y de castigo.

Sentí enojo hacía mí, porque en ese tiempo me comporté de lo peor, cuando me enfermé de eso quise tratarme de una manera muy mal; ya cuando supe que tenía esta enfermedad dije ¿por qué a mí?, si no era para tanto que yo me enfermara de esta manera; pero sí me arrepentí muchísimo de cómo me haya portado en ese entonces. Yo me fui mucho a mis amigos, empecé a tomar, salía yo con mis amigos, llegaba tarde, a las cinco de la mañana, a las dos de la mañana, y así. Sí, me divertí, pero eso tuvo una consecuencia (21 años de edad, sin hijos/hijas).

Porque él era casado, yo sabía. Y dejó una niña de tres años con su primera esposa. Y sí es pecado, porque yo sabía que era casado, que tenía su familia. Yo voy y me meto ahí, ahora sí que a cada quien le toca lo que está viviendo. Yo lo tomo así, es como una lección para que yo aprenda a tomar una buena decisión. Y, bueno, ahora las consecuencias son éstas, ni modo ahora a arrepentirse (24 años, una hija fallecida por enfermedad asociada al VIH).

Este debate entre los culpables y las víctimas se reproduce y se complejiza con la presencia de los hijos o hijas. Se destaca la inocencia de ellos y ellas o de los que podrían venir. Así, las mujeres se posicionan como posibles victimarias. "Esa pareja mía era mi primer pareja. Ahora sí que hay de hombres a hombres. El doctor me regañó: ¿̨por qué no te cuidaste? A hora mira las consecuencias de la niña” (24 años, una hija fallecida por enfermedad asociada al VIH). 


\section{TRAER UN HIJO O HIJA AL MUNDO}

Esta categoría nos permitió conocer acerca de los significados que las mujeres atribuyen a los nuevos embarazos viviendo con VIH. Traer hijos o hijas al mundo es una frase que se repite en las narraciones; además es muy utilizada como expresión popular. En este caso, es una connotación mediada por dos discursos que representan los significados sobre la maternidad y el VIH o el sida.

El tema recurrente de la maternidad generó tensión. Se revelaron dudas, preocupaciones y conflictos personales, de pareja, familiares y médicos. Diferentes miradas conformaron esta categoría; principalmente, las vivencias propias narradas por las participantes y, en menor medida, las opiniones sobre otras mujeres o parejas, así como la intervención de otros actores como el personal de salud, la familia y, en algunos casos, la religión.

En este contexto, los principales conflictos identificados se explican en relación con el deseo, la posibilidad y el deber. Puntualizando en los juicios de valor otorgados a la posibilidad de tener hijos o hijas se vislumbran mejor estos entredichos.

Sería muy egoísta de mi parte, sí, porque ya es definitivo que salga con el virus, ¿verdad? (25 años de edad, con una hija sin $\mathrm{VIH}$ ).

Yo no quisiera tener un bebé; simple y sencillamente no puedo. A veces yo misma me desanimo y dejo de tomar el medicamento. Y de que yo tenga un bebéy que salga infectado, no se me hace justo traer un bebéasí (24 años, una hija fallecida por enfermedad relacionada con el VIH).

Es delicado y tener mucho cuidado con todo eso. Y pues yo diría ¿para quétraer más niños al mundo de esa forma? Ya de ahí, bueno, tener relaciones entre ellos; que tengan, pero más niños así, no. Yo en eso sí, no estoy de acuerdo con eso de tener más hijos. Es algo difícil. Yo digo a veces, será que a ellos no les duele, pues... o por qué no lo piensan, ¿para qué traer más hijos a sufrir? Porque vienen a sufrir. Que ya padecen de esto, que ya se enfermaron de esto. Si así anda uno, ahora cómo será en un niño. Yo debo ya dejarlo ahí, porque yo diría que qué caso tiene de que el niño venga a sufrir, o no vivir su vida como es o estar con tratamiento, o no sé... qué tanto puede vivir un niño con el tratamiento ( 40 años, viuda, dos hijas y un hijo, ninguno vive con VIH).

Lo injusto, lo egoísta, la imposibilidad y el sinsentido con los que se concibe esta situación tienen como protagonista la probabilidad de la transmisión. Este riesgo no se reduce sólo al virus, sino se extiende y se configura en la posibilidad de daño 
a los hijos e hijas. El daño se piensa en términos de sufrimiento, y se relaciona con lo que significa para ellas vivir con VIH, lo cual implica seguir un tratamiento de por vida, la posibilidad de la muerte, de enfermedad y el rechazo de parte de otras personas.

En este conflicto, las mujeres se perciben y son percibidas como quienes pueden evitar o dar este "sufrimiento". Esto da lugar a la culpa y la responsabilidad, lo que implica que el o la que viene es la víctima. En este sentido, entendemos que se está satisfaciendo un deseo y un querer sin pensar en ese otro u otra, lo cual es valorado de manera negativa. La concepción idealizada positivamente de ser madre se convierte en un hecho casi inconcebible. Se contrapone aquíla ilusión de ser madre, que en las narraciones de las participantes es expresada como naturalmente compartida por las mujeres, con la imposibilidad de serlo debido a un juicio de irresponsabilidad por dar vida a alguien que, desde la idea de la mayoría de las entrevistadas, viene a sufrir, a padecer una enfermedad que no permite llevar a cabo una vida "normal", en palabras de ellas.

La culpa ocupa el sentir de todas ellas en algún punto de su experiencia y al pensar en el embarazo. Sentirse culpable o ser culpada implica una valoración negativa por haber cometido un acto que no es aceptable, que, por lo tanto, se encuentra asociado a la noción de lo que está bien y lo que no está bien, y puede vivirse con angustia.

Pues, es que yo digo que no, porque si sale enfermo pues yo voy a tener la culpa; el bebé no tiene la culpa. Sí, porque yo sé que estoy enferma y todavía voy a traer un bebé... [llora] no, no quiero... Yo veo pues a mi hijo que está enfermo, y a él lo voy a cuidar, lo voy a querer mucho, pues necesita mucho de mí y yo a él también (21 años, un hijo que vive con VIH).

Este sentir se encuentra establecido bajo la idea de la responsabilidad por el daño y el sufrimiento, cuestiones incompatibles en la relación madre e hijo/hija, y se agrava porque existen pocos espacios para reflexionar sobre sus experiencias, dudas y miedos. Traer un hijo o hija al mundo significa, en este contexto, ser responsable del riesgo de que esa persona sea rechazada, que tenga una vida "fuera de lo normal", concepción pensada desde la experiencia de cada una, pero también en relación con la connotación social de estigma hacia el VIH. 


\section{HABLAR DEL VIH CON LOS HIJOS O HIJAS}

En general, hablar acerca del padecimiento fuera del contexto médico representó una dificultad para las mujeres. Relataron episodios de rechazo por parte de familiares y expresaron el temor de comentarlo a nuevas personas. La presencia de los hijos o hijas en este dilema es fuente de preocupación.

Abordar este tema es hablar de las posibilidades de rechazo, de lo imaginado por ellas en relación con los otros, de aquello que se relaciona con su propio padecer y trasciende a la vida de los hijos e hijas. Este evento imaginado se asocia principalmente con cuestiones negativas, al tiempo que otras posibilidades son obviadas, lo cual ha sido documentado en investigaciones (Pecheny et al., 2012). Sostienen que cuando los hijos saben del diagnóstico suelen acompañar y participar de los cuidados y toma de medicamentos.

La forma en que se piensa este evento difiere según las circunstancias en aquellas que tienen hijos que viven con y sin VIH. En general, es un evento que se proyecta hacia el futuro. La adolescencia es la etapa percibida por todas como la más adecuada para afrontarlo, por el inicio de las relaciones sexuales y la madurez para comprender la situación.

En particular, para las mujeres que tienen hijos que viven con VIH, éste es un tema que genera mayores tensiones. La transmisión se vive con culpa y responsabilidad, aun en aquellos casos en los que ellas han expresado e identificado a sus parejas como "los culpables", refiriéndose al comportamiento de ellos. Gran parte de los sentimientos, como la culpa y la angustia, devienen al pensar en cómo será la vida de sus hijos. Se proyectan y se imaginan limitaciones, producto de la manera en que se piensa el padecimiento. ¿Podrán tener hijos o hijas?, ¿casarse?, ¿tener relaciones sexuales?, se preguntan.

Uno de los conflictos más importantes se encuentra entre la importancia de que conozcan que viven con VIH y las posibles consecuencias negativas de esa situación.

Pues yo no quiero que al decirle que está enfermo, yo no quiero que se sienta mal. Es que no es tan fácil de escuchar qué es lo que tiene (21 años, un hijo que vive con VIH).

Eso es lo que yo no sé, cómo va a ser su vida, no sé si... no sé qué va a pensar cuando esté más grande, si yo no lo logro ver crecer, que esté así, muchacho, no sé cómo va a reaccionar a que yo se lo diga... (27 años, un hijo que vive con VIH). 
El sentimiento de culpa por la transmisión del VIH se manifiesta en la idea del rechazo de parte de sus hijos o hijas, incluso se menciona el odio. Ellas expresan lo difícil que sería afrontar el rechazo de un hijo o hija; presentaría más dificultad que ser señaladas por otras personas. Esta posibilidad imaginada resulta compleja, pues es difícil pensar en el odio o el rechazo de parte de un hijo o hija cuando en el modelo de la maternidad no hay espacio para otros sentimientos más allá de amor (Badinter, 1981).

En cuanto a la relación madre-hijo en que ambos viven con VIH, desde la visión de la madre, el hijo se convierte en una persona que puede condenarla, evaluarla y juzgarla por la transmisión. Los hijos e hijas pueden convertirse en aquellos que juzgan el papel de madre, a ella en su función, más allá de la transmisión. En este sentido, se comparte la idea de que fallaron como madres, que encierra la idealización de la maternidad, y sobre lo bueno y lo malo.

Algún día le tengo que contar que cuando estaba chiquito le detectaron esa enfermedad, pero ni sabe cómo... Más bien no quiero ni que crezca. Que se quede así chiquito. Sí... ya hasta sabe cuánto es lo que debe de tomar. Dice: mami mi pastilla... Entonces yo digo: ay, cuando sea grande, cómo le voy a decir. Ay, no sé si me vaya a odiar, no sé... (27 años, un hijo que vive con $\mathrm{VIH})$.

El temor al rechazo también está presente en aquellos casos en los que los hijos o hijas no viven con VIH. Es decir, ellas creen que es igualmente necesario que sus hijos o hijas sepan que ellas viven con VIH, que conozcan sobre el fallecimiento de sus padres y las circunstancias en torno a esa situación. Este rechazo imaginado da cuenta de que la posibilidad de "dañar" a sus hijos o hijas trasciende la transmisión y se proyecta al momento en que se hable del tema. Es interesante este punto porque, aun cuando el VIH no está presente en la relación, pues no hubo transmisión, el miedo al rechazo persiste. Este temor puede responder a otros elementos relacionados con una imagen de sí misma que no corresponde a la idealización de ser madre, y ello incluso justifica o predispone al rechazo.

Ahora estoy mucho más tranquila, mucho más tranquila de saber que no lo tiene, que nunca lo tuvo. Pero me va a dar miedo que cuando crezca se vaya a contagiar por equis o ye razón. Pero ahora no me siento tan incompetente o frágil, o algo así, o hay otra palabra que no se me ocurre, que tiene que ver con fragilidad. Pero, bueno, ahora me siento un poquito más fuerte para poder con él y con mis hijos. Pero el que me da temor es mi hijito; comentarle y 
platicarle lo que tengo, que sepa que él nació, pero que tiene una mamá que está infectada. No sé qué palabra usar, pero sí me da miedo comentarle, a lo mejor siento rechazo comentarle, hacia mí (30 años, dos hijos sin VIH).

La proyección hacia el futuro da lugar a la incertidumbre, permite imaginarse cómo será la reacción, cómo será vista y tratada. El panorama continúa estructurándose dentro de la estigmatización y la culpa.

\section{DE MADRE A HIJO/HIJA: LO QUE LE DEJÉ}

El sufrimiento pensado, recurrente en las narraciones, se relaciona con la imposibilidad de vivir una sexualidad plena, el rechazo y la imposibilidad de formar una familia. En este escenario, la madre es la que toma la responsabilidad al respecto.

Pues por la enfermedad, yo pienso que me va a rechazar porque está enfermo. Este, yo no pude darle vida asísano. Yo sé que se ve sano, pero no sé (21 años, un hijo que vive con VIH).

Como a mí que me dijeron que la persona con la que me casé estaba infectada, yo traje al mundo un bebé, que sé que sufrió mucho. Hice todo lo que estaba en mis manos para salvarla, pero no pude hacer nada ( 24 años, una bebé fallecida por una enfermedad relacionada con el VIH).

Esta situación puede interpretarse como una contradicción: por un lado, existen expectativas de virtud, pureza, bondad, creación y protección pensadas como intrínsecas a la maternidad; por el otro, la posibilidad del daño, que se manifiesta en el sentimiento de haber fallado, en la culpa, en la incompatibilidad de pensar en la maternidad viviendo con VIH o sida (Long, 2009). Lo incompatible es justamente lo incongruente que resulta pensar en una madre que daña a su hijo o hija. Así lo expresó otra de las participantes, diagnosticada en el embarazo, al describir lo que sentía cuando estaba en la expectativa de saber si su hijo que iba a nacer tenía VIH: "No te imaginas cómo yo tenía mucha conciencia hacia el hijo que había traído al mundo, me sentía culpable, totalmente culpable" (30 años, dos hijos sin VIH). 


\section{Conclusiones}

Los resultados permiten ver cómo los significados atribuidos al padecimiento, las metáforas y significaciones en torno al VIH y al sida condicionan cambios en las personas, donde se transforman aspectos de la vida cotidiana y de las relaciones sociales.

En este contexto, identificamos algunos significados que surgieron al pensar en la maternidad como posibilidad o como experiencia pasada y presente. Los ideales que suponen que la ilusión de ser madres corresponde a todas las mujeres, que una madre da todo por sus hijos, que la maternidad es una función casi exclusiva de las mujeres y hacen del cuidado y la protección una tarea primordial, entran en tensión y hasta contradicción al pensar en la posibilidad de transmisión del virus o en la transmisión misma. Estas contradicciones se conforman de aspiraciones, exigencias y mandatos (Sanhueza, 2005), y se viven de manera particular en cada una de las experiencias.

La idea del riesgo de la transmisión en relación con la posibilidad de tener hijos o hijas se configura en torno al sufrimiento. Las mujeres se piensan y son pensadas en la posición de ser las potenciales responsables del mismo riesgo, por lo que sobre ellas recae la culpa. El sufrimiento se justifica en la enfermedad, el tratamiento continuo y la posibilidad de muerte que han experimentado y de los que han sido testigos. Asimismo piensan en los obstáculos en la vida futura, formar una familia, tener relaciones sexuales, ser rechazado o rechazada. De tal manera, se construye una idea de imposibilidad de tener hijos o hijas, cuyo origen se encuentra en aspectos sociales, que son reproducidos por diferentes actores.

La resignificación de la maternidad como riesgo, sobre todo en relación con el embarazo, demuestra cómo se complejiza la situación en términos del estigma, describiendo procesos que se proyectan y se piensan en el futuro. La culpa por la transmisión es determinante para entender la idea de riesgo, pero la ausencia de la transmisión no es garantía de tranquilidad. Los temores derivados de revelar a sus hijos o hijas que se vive con VIH y el miedo al rechazo dan cuenta de procesos de culpabilidad que trasciende la transmisión hacia una imagen de madre que puede ser juzgada, la cual tiene sus raíces en las idealizaciones sobre lo bueno de ser madre (Palomar, 2004).

En el análisis de las narraciones se identificaron conflictos y preocupaciones que surgen en relación con la maternidad y al hecho de vivir con VIH. Así, se logró un acercamiento a las lógicas subyacentes en las tensiones, que se viven en la historia y el contexto de cada una de las mujeres. Las diferentes experiencias y situaciones 
vinculadas con la maternidad le dieron riqueza al análisis y amplificaron los elementos explicativos y la comprensión.

Cada una de las narraciones de las mujeres que participaron en esta investigación revela aspectos personales y da cuenta de procesos sociales. Ello permitió, además de profundizar en cada una de las historias, conocer el marco de valores que funciona detrás de las decisiones, opiniones y conflictos. El sufrimiento sentido, las experiencias de violencia y de rechazo que han vivido nos hablan de una realidad u orden social que margina y aísla desde el prejuicio. Los valores sociales que estigmatizan a las personas que viven con VIH o sida, y a estas mujeres en particular, tienen eco desde ellas mismas: se saben inmersas en un sistema de valores que de por sí juzga con mayor severidad las formas no consensuadas de sexualidad femenina, y con la presencia de la enfermedad, ante los otros, este juicio se sugiere fuertemente. Es decir, se trata de un estigma que habita en ellas mismas, allí se fincan sus temores, pero es un eco del entorno en relación con la sospecha que despierta el hecho de que cualquier mujer padezca alguna enfermedad de transmisión sexual.

En este sentido, Mendes (2012) menciona que para sobrevivir al diagnóstico hay que revelarse contra el mandato cultural, informarse correctamente y ampliar las redes para conocer a otras personas que viven con VIH. Sin ánimo de ser una receta para el éxito, alienta al cuestionamiento de lo que se cree verdad, y dirige la mirada hacia lo social. Además, rescata el carácter de agencia que tienen las personas; estas no son pasivas a los discursos, sino que reelaboran y toman decisiones según lo que estén viviendo, por lo que pueden cambiar la manera de vivir.

Durante el trabajo de campo nos dimos cuenta de la escasez de espacios, fuera del consultorio médico, en los que las personas puedan expresar, compartir, retroalimentar y conocer otras experiencias. En el Hospital no se ofrecen espacios diferentes, que complementen el seguimiento médico de las personas, con herramientas, que trabajen más allá de la medicación y el control periódico de los síntomas. Frente a ello, surgió la recomendación de crear escenarios en donde las personas logren reconocerse y trascender prejuicios, así como trabajar las dudas de forma colectiva. 


\section{BibLIOgRAFÍA}

BADINTER, E. (1981). ¿Existe el amor maternal? Historia del amor maternal. Siglos XVII al XX. Barcelona, España: Paidós.

Bertaux, D. (1980). L'approche biographique: Sa validité méthodologique, ses potentialités. Cabiers Internationaux de Sociologie, 59(1): 247-248. Recuperado de http:// www.jstor.org/stable/40689912.

Bertaux, D. (1999). El enfoque biográfico. Su validez metodológica, sus potencialidades. Proposiciones, 29(marzo): 197-225. Recuperado de www.sitiosur.cl/publicaciones/ Revista_Proposiciones/PR-0029-3258.pdf.

BIAGINI, G.; Grigaitis, L., y Giri, B. (2008). Embarazo y VIH/sida: Vivencias del proceso salud-enfermedad-atención: Un estudio de casos de mujeres seropositivas embarazadas atendidas en efectorespúblicos seleccionados. Buenos Aires, Argentina: Instituto de Investigaciones Gino Germani, Facultad de Ciencias Sociales, Universidad de Buenos Aires.

Castro, R. (1996). En busca del significado: Supuestos, alcances y limitaciones del análisis cualitativo. En I. Szasz y S. Lerner (comps.). Para comprender la subjetividad. Investigación cualitativa en salud reproductiva y sociedad (pp. 55-85). Distrito Federal, México: El Colegio de México. Recuperado de http://www.academia. edu/13002204/En_busca_del_significado_supuestos_alcances_y_limitaciones_del_análsis_cualitativo.

CDI (Comisión Nacional para el Desarrollo de los Pueblos Indígenas) (2011). Informe final de la consulta sobre VIH-sida y pueblos indigenas en áreas fronterizas. Distrito Federal, México: Comisión Nacional para el Desarrollo de los Pueblos Indígenas. Recuperado de https://avispasenaccion.files.wordpress.com/2012/02/informecdi-vih-prueba-final.pdf.

CENSIDA (Centro Nacional para la Prevención y el Control del VIH/SIDA) (2014). Vigilancia epidemiológica de casos de VIH/SIDA en México. Registro Nacional de Casos de SIDA Actualización al cierre de 2014. Distrito Federal, México: Secretaría de Salud, Dirección General de Epidemiología, Centro Nacional para la Prevención y el Control del VIH/SIDA. Recuperado de http://www.censida.salud.gob.mx/ descargas/epidemiologia/RN_CIERRE_2014.pdf

CENSIDA (Centro Nacional para la Prevención y el Control del VIH/SIDA) (2014) Mujeres y el VIH y el sida. Distrito Federal, México: Centro Nacional para la Prevención y el Control del VIH/SIDA. Recuperado de http://www.censida.salud. gob.mx/descargas/epidemiologia/M_V_S.pdf. 
CENSIDA (Centro Nacional para la Prevención y el Control del VIH/SIDA) (2009). El VIH/SIDA en México 2009. Distrito Federal, México: Centro Nacional para la Prevención y el Control del VIH/SIDA. Recuperado de http://www.censida.salud. gob.mx/descargas/2009/VIHSIDAenMexico2009.pdf.

Coffey, A., y Atkinson, P. (2003). Encontrar el sentido a los datos cualitativos. Estrategias complementarias de investigación. Medellín, Colombia: Universidad de Antioquia. Cornejo, M.; Mendoza, F., y Rojas, R. (2008). La investigación con relatos de vida: Pista y opciones del diseño metodológico. Psyke, 17(1): 29-39. DOI:10.4067/ S0718-222820080001000189.

Everingham, C. (1997). Maternidad: Autonomía y dependencia. Un estudio desde la psicología. Madrid, España: Narcea.

Gogna, M.; Pecheny, M.; Ibarlucía, I.; Manzelli, H., y Barrón, S. (2009). The reproductive needs and rights of people living with HIV in Argentina: Health service users' and providers' perspectivas. Social Science \& Medicine, 69(6): 813-820. DOI: 10.1016/j.socscimed.2009.06.002.

Goffman, E. (2006). La identidad deteriorada. Buenos Aires, Argentina: Amorrortu. GRIMBERG, M. (2003). Narrativas del cuerpo. Experiencia cotidiana y género en personas que viven con VIH. Cuadernos de Antropología Social, 17(1): 79-99. Recuperado de http://www.scielo.org.ar/scielo.php?script=sci_arttext\&pid=S1850275X2003000100005.

Herrera, C.; Campero, L.; Caballero, M.; Kendall, T., y Quiroz, A. (2009). Cuerpo y sexualidad en la experiencia de hombres y mujeres con VIH: Una exploración de diferencias y coincidencias de género en México. Estudios Sociológicos, 27(79): 147-170. Recuperado de http://www.redalyc.org/articulo.oa?id=59820689005.

INGRAM, D., y Hutchinson, S. (2010). HIV-positive mothers and stigma. Health care for Women International, 20(1): 93-103. DOI: 10.1080/073993399245999.

Kendall, T., y Pérez, H. (2004). Hablan las mujeresmexicanas VIH positivas. Necesidades y apoyos en el ámbito. Distrito Federal, México: Colectivo Sol.

Kleinman, A. (1988). The Meaning of Symptoms and Disorders. The Personal and Social Meanings of Illness. En The Illness Narratives (pp. 3-31). Nueva York, Estados Unidos: Basic Books.

Lartigue, T.; Casanova, G.; Ortiz, J., y Aranda, C. (2004). Indicadores de malestar emocional y depresión en mujeres embarazadas con ITS-VIH/SIDA. Perinatología y Reproducción Humana, 18(2): 73-90. Recuperado de http://bvssida.insp.mx/ articulos/4299.pdf. 
Long, C. (2009). Contradicting Maternity: HIV-positive Motherhood in South Africa. Johannesburgo, Sudáfrica: Wits University Press.

Loutfy, M.; Sonnenberg Shwan, U.; Margolese, S., y Sherr, L. (2013). A living with HIV. AIDS Care, 25(6): 657-66.

Martínez, A. (2008). Genes, enfermedades y determinismos. Una crítica al modelo biomédico. En Antropología médica. Teorías sobre la cultura, el poder y la enfermedad (pp. 45-81). Barcelona, España: Anthropos.

Mendes, C. (2012). Sida y poder. Buenos Aires, Argentina: Madre Selva.

MenéndeZ, E. (1997). El punto de vista del actor homogeneidad, diferencia e historicidad. Relaciones, 18(69): 237-270.

Mercado Martínez, F.; Silva, L.; Ramos, I.; Leal, N., y Hernández, E (1999). La perspectiva de los sujetos enfermos. Reflexiones sobre pasado, presente y futuro de la experiencia del padecimiento crónico. Saúde Pública, 15(1): 179-186. http:// dx.doi.org/10.1590/S0102-311X1999000100018.

ONUSIDA (Programa Conjunto de las Naciones Unidas Sobre el VIH-Sida) (2011). Orientaciones terminológicas de ONUSIDA. Recuperado de http://nicaragua.unfpa. org/sites/lac.unfpa.org/files/pub-pdf/JC2118_terminology-guidelines_es_0.pdf.

Palomar, C. (2004). Malas madres: La construcción social de la maternidad. El Debate Feminista,30(15): 12-34. Recuperado de http://www.debatefeminista.pueg.unam. $\mathrm{mx} /$ wp-content/uploads/2016/03/articulos/030_02.pdf.

Palomar, C., y Suarez, M. E. (2007). Los entretelones de la maternidad. A la luz de las mujeres filicidas. Estudios Sociológicos, XXV(74):309-340. Recuperado de http:// www.redalyc.org/articulo.oa?id=59825202.

PARKer, R., y Aggleton, P. (2002). El estigma y sus efectos discapacitadotes. Suplemento S. Texto editado del estudio HIV and AIDS-Related Stigma and Discrimination. Aconceptual Framework and Implication for Action. Recuperado de http://www. equidadecuador.org/es/todo/ATT1121345190-1.pdf.

Pecheny, M.; Binstock, G.; Manzelli, H.; Hiller, R., y Bruno, M. (2012). Caracterización de las mujeres recientemente diagnosticadas con VIH en Argentina. Resumen ejecutivo 2012. Buenos Aires, Argentina: Instituto de Investigaciones Gino Germani, Red Bonaerense de Personas Viviendo con VIH-SIDA, Red Argentina de Mujeres Viviendo con VIH/sida, Centro de Estudios de Población, Fondo de Población de las Naciones Unidas, Fondo de las Naciones Unidas para la Infancia, ONUSIDA, ONUMUJERES, Organización Panamericana de la Salud, Ministerio de Salud. Recuperado de http://publicaciones.ops.org.ar/publicaciones/publicaciones\%20 virtuales/MujeresVIHPV/pdf/REjecutivoMujeresVIH.pdf. 
Pedrosa, L. (2004). Saberse infectadas. Repercusiones de la detección de VIH en mujeres. Desacatos (15-16): 148-170. Recuperado de http://desacatos.ciesas.edu.mx/index. $\mathrm{php} /$ Desacatos/article/view/1076/924.

Ponce, N. (2010). Lo cualitativo como estrategia de investigación: Apuntes y reflexiones. En P. Mejía, J. M. Juárez y S. Comboni (coords.). El arte de investigar (pp. 213231). Distrito Federal, México: Universidad Autónoma Metropolitan Unidad Xochimilco. Recuperado de http://dcsh.xoc.uam.mx/politicacultura/Escaneados/ EL\%20ARTE\%20DE\%20INVESTIGAR\%202.pdf.

Rodríguez, N. (2010). Procesos de resignificación a partir del diagnóstico de VIH/sida. En C. Hidalgo (comp.). Etnografías de la muerte. Rituales, desapariciones, VIH/ sida y resignificación de la vida. Buenos Aires, Argentina: Centro de Integración, Comunicación, Cultura y Sociedad, Consejo Latinoamericano de Ciencia Sociales. Recuperado de http://www.sidastudi.org/resources/inmagic-img/DD21146.pdf. Saletti, L. (2008). Propuestas teóricas feministas en relación al concepto de maternidad. Clepsydra (7): 169-183. Recuperado de https://es.scribd.com/ document/109681556/A-Propuesta-Teorica-Feminista-Del-Concepto-de-Maternidad.

SAnhueza, T. (2005). De prácticas y significancias en la maternidad, transformaciones en identidad de género en América Latina. La ventana (22): 146-188. Recuperado de http://www.redalyc.org/articulo.oa?id=88402208.

Segurado, C., y Paiva, V. (2007). Rights of HIV Positive People to Sexual and Reproductive Health: Parenthood. Reproductive Health Matters, 15 (29 Suppl): 27- 45. DOI: 10.1016/S0968-8080(07)29032-9.

Tubert, S. (1996). Figuras de la madre. Madrid, España: Ediciones Cátedra.

VELA, F. (2001). Un acto metodológico básico de la investigación social: La entrevista cualitativa. En M. L. Tarrés (coord.). Observar, escuchar y comprender. Sobre la tradición cualitativa en la investigación social (pp. 63-95). Distrito Federal, México: Porrúa, Facultad Latinoamericana de Ciencias Sociales. 